\title{
Capsule Commentary on Halm et al., Association Between Primary Care Visits and Colorectal Cancer Screening Outcomes in the Era of Population Health Outreach
}

\author{
Archana Radhakrishnan, MD MHS \\ J Gen Intern Med 31(10): 1220 \\ DOI: $10.1007 / \mathrm{s} 11606-016-3791-2$ \\ (c) Society of General Internal Medicine 2016
}

Johns Hopkins University School of Medicine, Baltimore, MD, USA.

$\mathrm{T}$ he purpose of the study by Halm et al. ${ }^{1}$ was to evaluate the role of primary care physicians (PCP) in colorectal cancer screening (CRC) and follow-up colonoscopy after positive fecal immunochemical (FIT) and fecal occult blood tests (FOBT). The authors looked at four different healthcare systems, three of which had various levels of organized screening outreach. Findings showed that patients who saw PCPs had higher rates of CRC screening and follow-up colonoscopy after positive FIT or FOBT tests.

Population-based initiatives are gaining popularity as a means of achieving cancer screening. ${ }^{2}$ The International Agency for Research on Cancer provides a framework for implementing effective population-based cancer screening programs which includes clearly defined screening policies, management teams for effective program implementation, healthcare teams for clinical decision-making, monitoring for cancer incidence and mortality, and quality assurance. ${ }^{3}$ The programs in this study fulfill many of the criteria; however, it is those patients who also had an interaction with their PCP who had higher CRC screening rates and follow-up colonoscopies. It is particularly notable that patients who saw their PCPs more than once had nearly twice the odds of undergoing screening.

This study provides important evidence that optimizing cancer screening rates likely requires a multi-pronged approach. Population-based programs have the capacity to reach large numbers of patients, but not at the expense of PCP involvement. The importance of the patient-PCP interaction cannot be underestimated. PCPs often have longitudinal relationships with their patients that naturally lend themselves to opportunities for educating and encouraging patients regarding preventive care. Atlas and colleagues found that patients who were more connected to their PCP were more likely to receive guidelineconsistent care, including higher rates of breast and cervical cancer screening, and chronic illness measures such as $\mathrm{HbA} 1 \mathrm{C}$ and LDL. ${ }^{4}$ Though patients may receive systembased reminders encouraging them to complete tests, their own PCP still remains a trusted source of information providing individual guidance towards achieving optimal health outcomes.

Corresponding Author: Archana Radhakrishnan, MD MHS; Johns Hopkins University School of Medicine, Baltimore, MD, USA (e-mail: aradhak3@jhu.edu).

\section{REFERENCES}

1. Halm EA, Beaber EF, McLerran D, Chubak J, Corley DA, Rutter CM, Doubeni CA, Haas JS, Balasubramanian BA. Association between primary care visits and colorectal cancer screening outcomes in the era of population health outreach. J Gen Intern Med. DOI: 10.1007/s11606-016-3760-9

2. Verma M, Sarfaty M, Brooks D, Wender RC. Population-based programs for increasing colorectal cancer screening in the United States. CA Cancer J Clin. 2015;65(6):497-510.

3. dos Santos Silva I. Cancer Epidemiology: Principles and Methods. Lyon, France: IARC Press; 1999.

4. Atlas SJ, Grant RW, Ferris TG, Chang Y, Barry MJ. Patient-physician connectedness and quality of primary care. Ann Intern Med. 2009;150:325335 . 